OPEN ACCESS

Edited by:

Erwan Mortier,

Centre National de la Recherche

Scientifique (CNRS), France

Reviewed by:

Giuseppe Fiume,

University of Catanzaro, Italy

Lutz Menzel,

Helmholtz Association of German

Research Centers (HZ), Germany

${ }^{*}$ Correspondence:

Erwan Dumontet

erwan.dumontet@chu-rennes.fr

Specialty section:

This article was submitted to

Cytokines and Soluble

Mediators in Immunity,

a section of the journal

Frontiers in Immunology

Received: 28 September 2021 Accepted: 23 November 2021 Published: 08 December 2021

Citation:

Dumontet E, Mancini SJC and Tarte K (2021) Bone Marrow Lymphoid Niche Adaptation to Mature B Cell Neoplasms.

Front. Immunol. 12:784691.

doi: 10.3389/fimmu.2021.784691

\section{Bone Marrow Lymphoid Niche Adaptation to Mature B Cell Neoplasms}

\author{
Erwan Dumontet ${ }^{1,2 *}$, Stéphane J. C. Mancini ${ }^{1}$ and Karin Tarte ${ }^{1,2}$ \\ 1 Univ Rennes, Institut National de la Santé et de la Recherche Médicale (INSERM), Établissement Français du Sang (EFS) \\ Bretagne, Unité Mixte de Recherche (UMR) U1236, Rennes, France, ${ }^{2} \mathrm{CHU}$ Rennes, Pôle de Biologie, Rennes, France
}

B-cell non-Hodgkin lymphoma (B-NHL) evolution and treatment are complicated by a high prevalence of relapses primarily due to the ability of malignant B cells to interact with tumor-supportive lymph node $(\mathrm{LN})$ and bone marrow $(B M)$ microenvironments. In particular, progressive alterations of BM stromal cells sustain the survival, proliferation, and drug resistance of tumor B cells during diffuse large B-cell lymphoma (DLBCL), follicular lymphoma (FL), and chronic lymphocytic leukemia (CLL). The current review describes how the crosstalk between BM stromal cells and lymphoma tumor cells triggers the establishment of the tumor supportive niche. DLBCL, FL, and CLL display distinct patterns of BM involvement, but in each case tumor-infiltrating stromal cells, corresponding to cancer-associated fibroblasts, exhibit specific phenotypic and functional features promoting the recruitment, adhesion, and survival of tumor cells. Tumor cell-derived extracellular vesicles have been recently proposed as playing a central role in triggering initial induction of tumor-supportive niches, notably within the BM. Finally, the disruption of the BM stroma reprogramming emerges as a promising therapeutic option in B-cell lymphomas. Targeting the crosstalk between BM stromal cells and malignant B cells, either through the inhibition of stroma-derived B-cell growth factors or through the mobilization of clonal B cells outside their supportive BM niche, should in particular be further evaluated as a way to avoid relapses by abrogating resistance niches.

Keywords: B-cell non-Hodgkin lymphomas, cancer-associated fibroblasts, extracellular vesicles, tumor microenvironment, stroma cell

\section{INTRODUCTION}

B-cell non-Hodgkin lymphomas (B-NHL) are a heterogeneous group of hematological malignancies that emerge from different stages of normal mature B-cell differentiation (1). Lymphoma evolution and treatment are complicated by a high prevalence of relapses (2) primarily due to the ability of malignant B cells to interact with protective lymph node (LN) and bone marrow (BM) microenvironments (3-5). In agreement, several studies have correlated BM involvement with worsened prognosis and impaired chemotherapeutic response in B-cell lymphomas (6-8). This review delves into the current knowledge of the BM stromal cell 
modifications induced by the protumoral niche establishment in B-NHL with a specific focus on diffuse large B-cell lymphoma (DLBCL), follicular lymphoma (FL), and chronic lymphocytic leukemia (CLL). Interestingly, these three B-NHL subtypes displayed various BM involvement, with $11 \%-34 \%$ of DLBCL $(9,10), 70 \%-80 \%$ of FL (11), and virtually all CLL cases showing BM infiltration at diagnosis (Table 1). Moreover, this review highlights the newly described role of extracellular vesicles (EVs) in the seeding of the BM niche. EVs are released during homeostasis and cell activation, with pleiotropic effects on signaling between cells. EV cargos are enriched in nucleic acids, proteins, and lipids. Briefly, the International Society of Extracellular Vesicles had classified EVs into three main groups: i) exosomes, the small vesicles with diameters $\leq 100-150 \mathrm{~nm}$ that are formed inside multivesicular bodies; ii) microvesicles, medium-size vesicles of plasma membrane origin with diameters of up to $1000 \mathrm{~nm}$; and iii) apoptotic bodies, the large vesicles with diameters $>1000 \mathrm{~nm}$ that are produced by apoptotic cells (12). Excellent reviews on the biomolecular and functional characteristics of EVs as well as on the techniques used for EV isolation and characterization have recently been published $(13,14)$.

DLBCL is the most common aggressive B-NHL and accounts for approximatively $24 \%$ of new NHL cases (15). Gene expression analysis and study of genomic alterations have identified distinct genetic subtypes in DLBCL, reflecting differential pathogenesis, and associated with distinct clinical behavior (16-19). Interestingly, recent studies have highlighted the impact of tumor microenvironment (TME) heterogeneity on tumor B-cell biological features and on DLBCL patient outcome $(20,21)$.

FL accounts for about $20 \%$ of adult lymphoma and is an indolent disease characterized by prolonged periods of remissions preceding relapses and ultimate transformation into DLBCL in about $30 \%$ of cases. The genetic hallmark of FL is the $t$ $(14,18)$ translocation occurring during the $\mathrm{V}(\mathrm{D}) \mathrm{J}$ recombination of immunoglobulin genes in the BM. The resulting deregulation of BCL2 provides a selective survival advantage to B cells during the germinal center (GC) reaction, triggering illegitimate recirculation of $\mathrm{t}(14,18)^{\text {pos }}$ post-GC B cells detectable in most healthy individuals. Iterative (re)entry of these FL precursor cells inside GC favors accumulation of additional genetic alterations sometimes converging towards overt FL (22). Importantly, FL is the paradigm of a neoplasia fully dependent on a complex microenvironment network that coevolves with tumor B cells to create a tumor supportive niche in both $\operatorname{LN}$ and $\operatorname{BM}(23,24)$.

CLL is the most common hematologic malignancy in adults in Western countries. CLL is preceded by a stage of monoclonal B-cell lymphocytosis and is characterized by the accumulation of mature clonal B cells resistant to apoptosis in the blood, BM, and lymphoid organs. Patients with CLL have a heterogeneous clinical course with some never needing treatment, while others require treatment immediately after diagnosis or during illness due to a more symptomatic and unfavorable clinical course. In typical CLL cases, the tumor B cell clone exhibits an abnormal expression of markers like CD5, CXCR4, and ZAP-70, that are used to stratify the disease in conjunction with the mutational status of the BCR reflecting different cell of origin (25, 26). Despite fully disseminated presentation, TME provides crucial survival signals to malignant CLL cells within the proliferation centers of LN and BM (27).

In these three mature B-cell neoplasms, specialized tumor niches support survival, proliferation, and drug resistance of tumor B cells. These highly heterogeneous niches include defective tumor immunity, due to altered recruitment and cell exhaustion of cytotoxic cells, to the amplification of immunosuppressive cells, or to immune escape mechanisms developed by tumor B cell themselves, hampering tumor recognition, immune synapse formation, or anti-tumor cell activation $(23,24,27)$. Conversely, fully functional tumor permissive cells, including $\mathrm{CD} 4^{\text {pos }} \mathrm{T}$ cell, myeloid cell, and stromal cell subsets, could be found. The relationship between LN and BM protumoral niches and how the similarities and differences between these microenvironments could impact malignant B-cell features remains elusive. In FL, malignant B cells found in the BM are characterized by a lower cytological grade, a decreased proliferation, and a reduced CD10 expression compared with LN FL B cells (28). Moreover, their gene expression profile reflects their reduced proliferation and active metabolism (29). Finally, somatic hypermutation analysis and targeted deep sequencing demonstrate that different FL B-cell subclones could be detected within LN versus BM, and suggested that FL originates in the LN and infiltrates BM early in the course of the disease, allowing further accumulation of BM-specific

TABLE 1 | Key elements involved in the generation of B-cell non-Hodgkin lymphomas bone marrow supportive niches.

\begin{tabular}{|c|c|c|c|}
\hline & DLBCL & $\mathbf{F L}$ & CLL \\
\hline BM involvement (\% of cases) & $11-34 \%$ & $70-80 \%$ & All \\
\hline Pattern & $\begin{array}{l}\text { Mixed: from localized focal infiltrates to } \\
\text { complete disruption }\end{array}$ & $\begin{array}{c}\text { Nodular aggregates admixed with } \\
\text { lymphoid-like TME }\end{array}$ & $\begin{array}{c}\text { Mixed nodular-interstitial, interstitial, and } \\
\text { diffuse }\end{array}$ \\
\hline $\begin{array}{l}\text { BM stroma factors involved in } \\
\text { B-cell homing }\end{array}$ & Unknown & $\begin{array}{c}\text { CXCL12 } \\
\text { CCL19, CXCL13 }\end{array}$ & CXCL12 and VLA-4 \\
\hline BM stroma factors involved in & BAFF & Hehghog ligands & BAFF, CD44, \\
\hline B-cell survival & IL-6 IL-17A & $\begin{array}{l}\text { BAFF, TGF- } \beta, \text { VLA-4, } \\
\text { CXCL12 }\end{array}$ & Plexin-B1, CXCL12, C1q \\
\hline $\begin{array}{l}\text { Metabolic reprogramming } \\
\text { induced by BM TME }\end{array}$ & Unknown. & $\begin{array}{c}\text { BM B cells are metabolically less } \\
\text { active than LN B cells }\end{array}$ & $\begin{array}{c}\text { BM stromal cells release glutathione and } \\
\text { trigger CLL glycolytic shift }\end{array}$ \\
\hline $\begin{array}{l}\text { Effects of tumor EVs on BM } \\
\text { stromal cells }\end{array}$ & Unknown. & $\begin{array}{c}\nearrow \mathrm{CXCL} 12, \nearrow \mathrm{ANGPT1}, \nearrow \mathrm{KITLG}, \\
\nearrow \mathrm{IL}-7\end{array}$ & $\begin{array}{c}\nearrow \text { VEGF } \\
\text { Inflammatory pro-tumoral phenotype }\end{array}$ \\
\hline
\end{tabular}


mutations $(28,30,31)$. Besides the exact cell composition and supportive signals provided by BM niches, a major issue remains to establish how these niches evolve during tumor development, from the pre-tumoral stage to overt lymphoma, during remissions and relapses.

\section{LYMPHOMA BM STROMAL MICROENVIRONMENT}

BM constitutes the primary site for the maintenance and differentiation of hematopoietic stem cells (HSCs) and for Bcell lymphopoiesis. Different stromal cell niches dynamically control these processes. Seminal papers have recently proposed a molecular atlas of the BM stromal cells at the single cell resolution, including osteoblasts, perivascular cells, endothelial cells, and mesenchymal stromal cells, providing clues on how various stromal cell subtypes could interact with HSCs and differentiating B-cell subsets (32-34). In the context of B-NHL, dynamic interactions between BM stromal cells and tumor B cells have been described to play a key role in converting the BM TME into a tumor supportive niche (34-36). DLBCL, FL, and CLL display distinct patterns of BM infiltration (Table 1). DLBCL show a mixed pattern of BM involvement that can potentially range from localized focal infiltrates to complete disruption of BM by lymphoma cell proliferation (37). In contrast, FL infiltration is primarily localized to the paratrabecular regions as nodular aggregates admixed with lymphoid-like TME (38). In CLL several BM infiltration patterns can be found including mixed nodular-interstitial, interstitial, and diffuse (39). In each cases, stromal cells exhibiting specific functional phenotype support recruitment, survival, and proliferation of tumor B cells, mimicking the cancer-associated fibroblasts (CAFs) described in solid cancers.

\section{BM Stromal Cells Support B-Cell Recruitment}

BM DLBCL-CAFs have been poorly explored in situ. In contrast, in FL, BM-CAFs, like their LN counterparts, overexpress CXCL12 involved in the recruitment, adhesion, and activation of FL B cells (40) (Table 1). Moreover, they ectopically express CXCL13 and CCL19, the two lymphoid chemokines classically expressed by LN follicular dendritic cells (FDC) and fibroblastic reticular cells (FRC) respectively, thus recreating GC-like structures able to recruit and support $\mathrm{CXCR}^{\text {pos }} \mathrm{CCR} 7^{\text {pos }} \mathrm{FL} \mathrm{B}$ cells $(41,42)$.

CLL B lymphocytes could be attracted in vitro to BM stromal cells whose protective effects require close cell proximity (43-45). This colocalization of CLL tumor cells with their supportive stromal cell niche relies on the deregulation of several chemokine pathways (Table 1). The demonstration that the clinical efficacy of BCR inhibitors in CLL is mediated, at least in part, by the inhibition of chemokine receptor activity and the corresponding mobilization of tumor cells out of their protective niches further highlights the crucial role of stromal cell-derived chemokine in CLL survival (46). First, high expression of CXCR4 on the surface of peripheral blood CLL cells triggers their migration to BM stromal cells producing CXCL12 (45, 47-49). CXCR4 surface expression is regulated by its ligand, thus explaining the decrease in CXCR4 expression on tissue tumor B cells, while recirculating CLL B cells express high levels of CXCR4. In parallel, blood CLL cells express high amounts of CCR7 (50). Indeed, the recycling of CXCR4 and CCR7 receptors is potentiated in CLL cells and contributes to their stronger expression (51). Recently, it was shown that p66Shc (SHCtransforming protein 1), which limits the recycling of CXCR4 and CCR7 by inhibiting their de-phosphorylation, is deficient in CLL (52). Interestingly, CCR7 could also form heterodimers with CXCR4 thus disrupting the CXCR4/CXCL12 downstream signaling and reducing B-cell retention within BM (53). Furthermore, other proteins expressed by CLL cells, such as ZAP70 or CXCR7 have been shown to regulate the function of CXCR4 $(54,55)$. Altogether, the modulation of CXCR4 function could regulate the homing capacity of CLL cells within BM. Second, CXCR5, the CXCL13 receptor, is also expressed at high levels by CLL cells $(56,57)$. However, conversely to the ectopic induction of CXCL13-expressing FDC in FL BM, CXCL13 seems to be only involved in CLL B cell homing into LN and the increase of CXCL13 level in the plasma of CLL patients is correlated with LN size but not BM infiltration (58). Finally, integrin $\alpha 4 \beta 1$ (VLA-4) plays a prominent role in the homing of CLL cells to BM niches. VLA-4 major ligands, fibronectin and VCAM-1, are constitutively present on BM stromal cells and endothelial cells and are upregulated by inflammatory signals in a NF-kB-dependent manner (59). In mouse xenograft models, CLL cells from VLA- $4^{\text {neg }}$ patients showed significantly lower BM homing rates than those from VLA $-4^{\text {pos }}$ patients. In contrast, the spleen homing rates did not significantly differ. Clinically, the VLA-4 status directly drives in the extent of human BM infiltration (60).

\section{BM Stromal Cells Support B-Cell Survival}

In DLBCL, the upregulation of Notch-3 in tumor cells under close cell-cell contact with BM-derived stromal cells has been implicated in the development of aggressive lymphoma cells (61). In turn, such direct interaction between DLBCL cells and stromal cells mediates an increase in B-cell activating factor (BAFF) expression by stromal thus resulting in a decrease of chemotherapy-induced B-cell apoptosis $(62,63)$ (Table 1). One of the factors involved in the regulation of DLBCL B-cell interaction with the BM stromal niche is the level of Jun expression. Indeed, Jun-regulated genes mediate the interaction of malignant cells with stromal cells and extracellular matrix proteins and impact extranodal localization (64). There is also evidence for tumor permissive effects of BM stromal cells on DLBCL cells through secretion of IL- 6 and IL-17A, which promote both cell proliferation and drug resistance (8). Finally, the crosstalk between malignant $\mathrm{B}$ cells and stromal cells in DLBCL could also impact metabolic reprogramming in DLBCL. DLBCL have been early considered as metabolically heterogeneous $(65,66)$. Non-malignant cells from TME including stromal cells have been proposed to contribute to DLBCL metabolism by providing metabolic intermediates (67) 
but no data specifically address this issue in BM versus $\mathrm{LN}$ niches even if the use of specific metabolic inhibitors have been recently explored in some DLBCL subsets (68).

In FL, tumor B cells are strongly dependent on direct interactions with a microenvironment close to that of normal GC, including in particular follicular helper T cells (Tfh), myeloid cells, and lymphoid stromal cell subsets $(23,24,69)$. The protumoral role of infiltrating lymphoid stromal cells has been demonstrated in particular by the identification of ectopicallyinduced FRC- and FDC-like cells within invaded BM (40, 70). To date the origin and heterogeneity of the stromal cells supporting FL B cells within LN and BM are not perfectly understood and it is very likely that several FL CAF subtypes co-exist and organize different cell niches with specific functions (38). Stromal cells supporting FL B cell survival have been initially identified as lymphoid-like stromal cells obtained in vitro by stimulation of BM mesenchymal precursors by TNF- $\alpha$ (TNF) and Lymphotoxin$\alpha 1 \beta 2$ (LT) or by direct contact with malignant B cells (3). Interestingly, BM stromal cells obtained from FL patients display a specific gene expression profile even after in vitro amplification, suggesting an imprinting on these cells by the tumor context $(40,63,71)$. VLA-4, which is expressed by FLCAFs, is involved in the growth of GC lymphomas and their resistance to anti-CD20 treatments (72). In vitro, FL stromal cells decrease tumor B cell apoptosis through a set of partially resolved mechanisms, including the production of hedgehog ligands $(\mathrm{Hh})$, BAFF and TGF- $\beta$, over- expression of ABC-type multi-drug transporters, and activation of a c-MYC/HDAC6 loop in tumor cells $(24,73)$. Moreover, CXCL12 contributes to FL B cell activation and synergize with BCR signaling (40). To date, the metabolism of FL remains broadly unexplored. Gene expression profile of FL B cells obtained from medullary niche reveals a decreased expression of the genes involved in of glycolysis, fatty acid synthesis, and OxPhos pathway compared to LN B cells (29). However, the role of stromal cells from BM versus LN niches in FL $\mathrm{B}$-cell metabolic reprogramming remains to be evaluated.

CLL B cells could interact with stromal cells via different receptor/ligand couples including ICAM-1/LFA-1 (74), VCAM-1/ VLA-4 (75-78), CXCR5/CXCL13 (79), BCMA/BAFF, or TACI/ BAFF (80), or by transpresentation of IL-15 from stromal cells to B cells (81). Amon those, ICAM-1, VCAM-1 and BAFF have been shown to be expressed by BM stromal cells. These interactions could lead to leukemic cell survival via a CD44-dependent mechanism involving up-regulation of MCL-1 in CLL B cells (82), activation of NF- $\kappa B$ pathway (80), and result in migration and proliferation of leukemic cells. In the same way, the interaction between CD100 (on CLL B-cell surface) and Plexin-B1 (present on BM stromal cells) extends CLL B cell viability and enhances proliferation (83). The mutual activation of stromal cells and tumor cells also depends on the CLL-mediated activation of Notch2 in BM stromal cells, leading to $\mathrm{Clq}$ overexpression the reciprocal activation of the canonical Wnt pathway in CLL cells (84) Moreover, BM stromal cell derived CXCL12 exhibits a pro-survival effect on CLL tumor cells $(44,85$, 86). BM Stromal cells may also induce protective epigenetic modifications in CLL B cells including hypomethylation of the lysine 27 of histone $\mathrm{H} 3$ protein subunit (H3K27me3) (87). Finally,
BM stromal cells have an important role on CLL metabolism. CLL cells have a net increase of reactive oxygen species (ROS) compared to their normal counterpart and are highly sensitive to cellular antioxydants, such as glutathione, to maintain their redox balance. BM stromal cells trigger glutathione synthesis by CLL cells through cysteine release, thus protecting tumor cells from drug-induced apoptosis (88). Moreover, BM stromal cells contribute to the glycolytic shift in CLL cells, at least in part by the Notch/Myc axis, triggering an increased glycolysis associated with higher lactic acid production, glucose uptake, and glucose transportation $(89,90)$.

\section{BM Stromal Cells Organize the Tumor Niche}

Beyond these functions of direct B-cell support, lymphoma CAFs are thought to be the organizers of the tumor niche. A role for the composition of the stromal-cell derived extracellular matrix in the pathogenesis of DLBCL was recently identified within tumor $\mathrm{LN}$, raising the question of its direct and indirect impact on tumor growth, as an example through the modulation of immune cell infiltration, within invaded BM (21).

FL-CAFs overexpress the chemokine CCL2 within invaded $\mathrm{BM}$, thus triggering the recruitment of monocytes that are then converted into pro-angiogenic and anti-inflammatory macrophages (71). FL tumor-associated macrophages have been shown to play a key role in the growth of FL B cells through the transpresentation of IL-15 and the triggering of BCR-dependent signaling involving DC-SIGN-expressing macrophages and oligomannose residues introduced in FL BCR $(91,92)$. BM and LN FL-CAFs could also promote the recruitment and survival of pro-tumoral neutrophils through the release of large amounts of IL-8 (63). Of note, in DLBCL, tumor cells have been shown to produce themselves IL- 8 involved in the recruitment of APRIL-producing neutrophils (93). Moreover, BM and LN FL-infiltrating stromal cells also overexpress the immunosuppressive molecule PGE2 (94) involved in the recruitment or activation of suppressor cells such as Tregs and MDSCs (95). Finally, CAFs have been shown in solid tumors to physically hamper the recruitment of cytotoxic $\mathrm{T}$ cells to the tumor and $\mathrm{CD}^{\text {pos }} \mathrm{T}$ cells are retained at the periphery of FL tumor aggregates in both LN and BM, suggesting that FL-CAFs could contribute to tumor exclusion in lymphomas (96-98).

Overall, it is clear that close interactions of tumor B cells with stromal cells within the BM, together with modulation of chemokines and cytokines directly influence the growth of DLBCL, FL and CLL, providing evidence that the BM niche plays a critical role in both lymphoma survival and drug resistance. Regardless of their cell of origin, the mechanisms underlying the differentiation of lymphoma CAFs are of the utmost importance given their potential as therapeutic targets.

\section{EMERGENCE OF THE BM LYMPHOMA STROMAL MICROENVIRONMENT}

FL tumor B cells could directly contribute to the commitment of $\mathrm{BM}$ stromal precursors into an FRC-like phenotype overexpressing 
CCL2 and IL-8 through TNF-dependent mechanisms $(3,63,71)$. Moreover, even if they produce less LT than normal centrocytes, the large number of GC-like B cells ectopically found in invaded FL $\mathrm{BM}$ probably contributes to a local overproduction of LT that synergizes with TNF for the induction of lymphoid stroma commitment. However, surrounding non-malignant cells could also participate in the polarization of FL-CAFs. Neutrophils, recruited by IL-8-producing BM FL stromal cells, could in turn contribute to their differentiation into FRC-like cells through activation of the NFKB pathway (63). In addition, LN FL-Tfh overexpress IL- 4 which induces a Transglutaminase ${ }^{\text {hi }}$ Podoplanin ${ }^{\text {low }}$ CD $106{ }^{\text {hi }}$ CXCL12 $2^{\text {hi }}$ phenotype on human stromal cell precursors. FL-Tfh also produce high amounts of TNF and LT, which sensitize stromal cell precursors to the effect of IL-4, notably through increased expression of the STAT6 signaling molecule (40). Even iffully mature Tfh have not been detected within FL BM, IL-4 and CXCL12 have been shown to be correlated in invaded FL BM (40). Finally, some of the recurrent genetic alterations in FL regulate the re-education of the tumor niche by tumor B cells. In particular, the gain-of-function mutations of the histone methyltransferase EZH2, which occurred early in $20 \%$ to $30 \%$ of FL, are proposed to uncouple GC B cells from the critical Tfh checkpoint whereas switching them to FDC dependency (99). EZH2-mutated GC B cells downregulate many genes linked to Tfh signaling, fail to engage Tfh, thus limiting recycling toward the dark zone of GC, and survive in the light zone as proliferating centrocytes overexpressing LT, TNF, and BAFFR, all involved in GC B-cell/FDC crosstalk. HVEM loss-of-function mutations detected in about $40 \%$ of patients with FL have been associated, in a murine model of FL and in FL patients, with an amplification of Tfh producing large amounts of IL4, TNF, and LT, and able to activate FL-CAF within LN (100). No study had currently evaluated how these genetic events could impact FL TME coevolution within BM. Even if such data are essentially lacking in the context of DLBCL, some recurrent genetic alterations have been recently associated with a specific TME pattern, with some of them related to overexpression of genes associated with GC-like stroma or extracellular matrix/FRC/CAF genes (21).

Finally, LT produced by CLL cells is involved in the polarization and/or in situ generation of the tumor stromal network and the secretion of CXCL13, IL-6, and IL-8 $(74,79)$. Moreover, the leukemic clone produces retinoic acid in the stromal microenvironment which contributes, at least in part, to the CXCL13 induction (101).

In addition to the factors described above, tumor derived EVs seem to be involved in the communication between tumor cells and their TME, in particular CAFs. Such mechanism could play a central role in triggering initial induction of tumor-supportive niche within distant sites, including BM.

\section{ROLES OF EVS IN THE INDUCTION OF BM LYMPHOMA STROMAL NICHE}

To date no study has explored the putative involvement of EVs in the induction of a BM lymphoma stromal niche in the context of DLBCL. Moreover, only few studies have investigated the involvement of EVs in the pathophysiology of FL (Figure 1).
Recently, FL-derived EVs were shown to modulate the gene expression profile of BM stromal cells, triggering an upregulation of HSC niche factors including CXCL12, angiopoetin-1, KITLG, or IL-7, and increasing the capacity of stromal cells to interact specifically with BM FL B cells and support their survival and their quiescent phenotype (29). Interestingly, the phenotype of EVtreated stromal cells is quite different from that obtained under treatment by TNF/LT or coculture with FL B cells supporting a role of EVs in the activation of BM stromal cells before BM seeding by malignant B cells. In fact, the level of CXCL12 is increased in noninvolved BM plasma suggesting that FL EVs could shape the BM stromal niche before BM infiltration by tumor cells or at distance from this BM infiltration (unpublished data). In the same way, the analysis of the gene expression profile of BM stromal cells highlights a continuum ranging from healthy donor BM stromal cells, to stromal cells obtained from FL patients without BM involvement, and finally from FL-invaded BM (29). Altogether these data suggest that EVs could contribute to CXCL12 upregulation in the absence of direct contact with malignant $\mathrm{B}$ cells and could then synergize with IL- 4 produced by infiltrating $\mathrm{T}$ cells admixed with FL B cells to further enhance local CXCL12 production. Interestingly, BM stromal cells activation by FLderived EVs was shown to rely on TGF- $\beta$ dependent pathways something that is reminiscent of the role of TGF- $\beta$ in the B-cell/ stromal cell crosstalk within FL LN (42). How TGF- $\beta$ and STAT6 pathways could synergize for the acquisition of FL CAF phenotype within FL BM remains to be explored.

Bidirectional crosstalk has also been reported between CLL Bcells and their surrounding stroma via EVs (Figure 1). CLL B cells release large amounts of exosomes that show strong expression of CD37, CD9, and CD63. Ibrutinib, a Btk inhibitor, significantly reduces the amount of plasma exosomes in CLL patients. Likewise, in vitro treatment of CLL cells with Idelalisib (a PI3K inhibitor) decreases exosome secretion, something that is not observed during treatment with fludarabine (102). This result highlights the role of the BCR-PI3K pathway in controlling exosome secretion in CLL. Besides BCR itself, CLL supportive TME produces BAFF, APRIL, CD31, and plexin B1 that all protect CLL cells from spontaneous apoptosis by synergizing with BCR signaling $(44,103)$ and could influence EV secretion. The comparison of the mRNA content of EVs produced by B cells from healthy donors versus patients with CLL, and stimulated or not through the TLR9 pathway, shows enrichment for the kinases of the BCR pathway, LYN, SYK, MAPK1, MAPK2, and the antiapoptotic proteins BCL2 and BCL3 in CLL-derived EVs. These EVs released by tumor $\mathrm{B}$ cells transfer their mRNA content to non-malignant cells in the TME (104). Microvesicles derived from malignant CLL cells and detected in peripheral blood also deliver the receptor tyrosine kinase Axl into BM stromal cells leading to the activation of a AKT/mTOR/p70S6K/HIF- $1 \alpha$ axis resulting in an increase in VEGF synthesis (105). This increase in VEGF is associated with an increased neovascularization in medullary (106) and extramedullary tissues, as well as a paracrine pro-survival stimulation of tumor B cells (107). The miRNA content of CLL B cell-derived exosomes is strongly enriched in miR-21, miR-155, miR-146a, miR-148a, and let-7g 


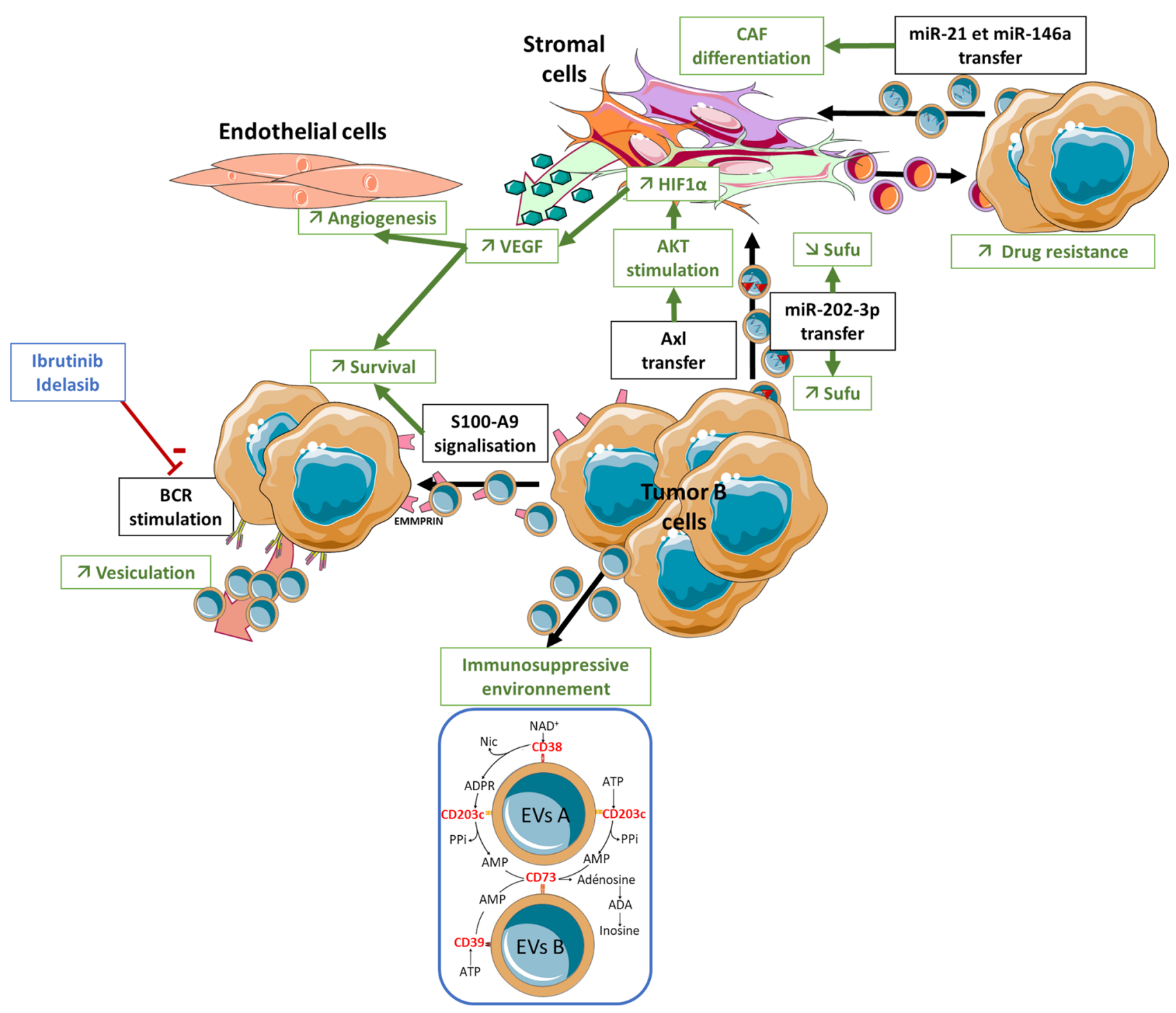

FIGURE 1 | Role of EVs in the lymphoma microenvironment structuration. A bidirectional crosstalk has been reported between CLL and FL tumor B-cells and stromal cells via EVs that can give rise to a highly organized pro-tumor niche. ANGPT, Angiopoietin; BCR, B Cell Receptor; BM, Bone Marrow; CAF, Cancer Associated Fibroblast; EVs, Extracellular Vesicles; TGF, Transforming Growth Factor- $\beta$; VEGF, Vascular Endothelial Growth Factor.

(108). BM stromal cells treated in vitro with these CLL exosomes acquire an inflammatory pro-tumoral phenotype, while endothelial cells increase their capacity for angiogenesis (108). These effects are consistent with what is known about the effect of miR-21 and miR-146a in the transition from normal fibroblast to CAFs (109-112). Indeed, CLL miR-146a ${ }^{\text {pos }}$ exosomes induce the transition of BM stromal precursors into CAFs showing overexpression of $\alpha$-SMA and FAP (113). In addition, CLL exosomes show specific enrichment in miR-202-3p, able to decrease expression of Sufu (a component of the hedgehog pathway) in stromal cells and to trigger stromal cell proliferation (114). Finally, EVs isolated from cultures of CLL BM stromal cells induce a significant decrease in spontaneous apoptosis of tumor B cells and an increase in their chemoresistance to several drugs, including fludarabine, ibrutinib, idelalisib, and venetoclax. In addition, these EVs induce changes in the gene expression profile of CLL cells mimicking the transcriptomic signatures obtained after BCR stimulation (115).

\section{DISRUPTING THE EV "REMOTE COMMUNICATION" TO IMPROVE LYMPHOMA PROGNOSIS}

Analyzing the deregulation of extracellular proteins or miRNAs in the blood and tumor niches of patients during B cell tumorigenesis is a reliable tool for the identification of new tumor-targeted therapies. For example, the detailed mode of action of the CD30 
antibody-drug conjugate Brentuximab vedotin in DLBCL is not well understood since the clinical outcome seems to be partially independent of the CD30 expression on the tumor cells. However, as $\mathrm{CD} 30^{\text {pos }}$ bystander cells are enriched in the tumor tissue in many cases of DLBCL, CD30 might be released within TME-derived EVs. Thus a model was proposed in which even in the absence of CD30 on the tumor cells, EVs can transport the targeting protein from cells of the TME to tumor cells (116). This model would explain the clinical efficacy of Brentuximab vedotin also in cases of lack of the targeting antigen on tumor cells. In the same way, DLBCL EVs carrying miR-125b-5p can reduce tumor sensitivity to rituximab by inhibiting TNFAIP3 expression and reducing CD20 expression (117). Whether the miR-125b-5p/TNFAIP3 axis can be used as a therapeutic approach for increasing DLBCL sensitivity to antiCD20 antibodies requires further investigations.

EVs released by B cell could carry CD39 and CD73, two surface molecules known to hydrolyze ATP released by dying cancer cells into adenosine that hijacks CD8 T cell immune activity by binding the A2A adenosine receptors (118). One could speculate that B-cell-derived EVs may have a similar effect. The decrease of B-cell-derived EVs bearing CD73 and CD39 can be achieved by deregulating the docking protein RAB27A (118). This could be performed using an inactivated Epstein-Barr virus carrying siRNA, but it is also possible to generate EVs derived from cell lines producing RAB27A siRNA and to specifically deliver it to tumor cells.

Ultimately, thanks to their molecular structure mimicking the plasma membrane of the cells and their capability to reverse their cargo into target cells, exosomes could be shaped and filled of drug molecules, acting as drug-delivery systems. In fact, cancer vaccine clinical trials relying on the administration of exosomes produced by dendritic cells (Dexosomes), exploited to shuttle antigenic determinants of immune response, were conducted to immunize patients in the context of solid tumors (119-121). In the same way, systemic administrations of TNF-Related Apoptosis-Inducing Ligand (TRAIL)-armed exosomes have shown a great anti-tumor effectiveness against FL/DLBCL cell lines both in vitro and in a mouse model (122).

\section{CONCLUSION}

Despite very interesting recent data highlighting BM as a survival niche for lymphoma B cells, numerous controversies remain open

\section{REFERENCES}

1. Lee SE, Kang SY, Yoo HY, Kim SJ, Kim WS, Ko YH. Clonal Relationships in Recurrent B-Cell Lymphomas. Oncotarget (2016) 7:12359-71. doi: 10.18632/oncotarget.7132

2. Nandagopal L, Mehta A. Treatment Approaches of Hard-to-Treat NonHodgkin Lymphomas. Expert Rev Hematol (2017) 10:259-73. doi: 10.1080/ 17474086.2017.1283214

3. Amé-Thomas P, Hajjami HM-E, Monvoisin C, Jean R, Monnier D, CauletMaugendre S, et al. Human Mesenchymal Stem Cells Isolated From Bone Marrow and Lymphoid Organs Support Tumor B-Cell Growth: Role of Stromal Cells in Follicular Lymphoma Pathogenesis. Blood (2007) 109:693702. doi: 10.1182/blood-2006-05-020800 on the role of the BM versus $\mathrm{LN}$ niches during the early step of lymphomagenesis or at the stage of post-treatment minimal residual disease that could generate relapse. In FL, both pretumoral B cells and early committed precursor cells, that will give rise to overt FL, have been shown to be enriched in BM (22). However, transformation events required iterative passages throughout the GC making it difficult to define precisely whether BM is a primary or a secondary tumor niche. The influence of tumor genetics or patient features on the capacity of tumor B cells to home and develop into BM remains completely unexplored. A major limitation for all BM-dedicated studies is the limited availability of good quality samples to perform phenotypic, transcriptomic, and functional studies and the lack of iterative sampling allowing evaluation of the impact of disease evolution or therapeutic strategies. BM aspirates are scarce and do probably not include the whole diversity of tumor/TME components, in particular stromal cells. Moreover, fixed BM biopsies are very difficult to exploit for spatial transcriptomics and even multiplex immunohistofluorescence approaches. Such technical issue hampers a precise evaluation of spatial heterogeneity in B-cell lymphomas integrating BM as a key tumor site.

Altogether, many evidence support the clinical interest of targeting the crosstalk between BM stromal cells and malignant $\mathrm{B}$ cells, through the inhibition of stroma-derived B-cell growth factors, the mobilization of clonal B cells outside their supportive $\mathrm{BM}$ niche, or the reprogramming of tumor-supportive stromal cells. Identifying the best therapeutic options, and how to combine them with tumor-targeting drugs or immunotherapy approaches will be the major challenge in the field.

\section{AUTHOR CONTRIBUTIONS}

ED wrote the paper, SM reviewed the paper, and KT supervised and wrote the paper. All authors contributed to the article and approved the submitted version.

\section{FUNDING}

This work was supported by research grants from Fondation ARC (PGA1 RF20170205386) and the Institut National du cancer (INCA AAP PNP19-009).

4. Wang D, Liu P, Zhang Y, Liu H-Y, Shen D, Che Y-Q. Bone Marrow Molecular Markers Associated With Relapsed/Refractory Activated B-CellLike Diffuse Large B-Cell Lymphoma. BioMed Res Int (2018) 2018: e1042597. doi: 10.1155/2018/1042597

5. Yao Z, Deng L, Xu-Monette ZY, Manyam GC, Jain P, Tzankov A, et al. Concordant Bone Marrow Involvement of Diffuse Large B-Cell Lymphoma Represents a Distinct Clinical and Biological Entity in the Era of Immunotherapy. Leukemia (2018) 32:353-63. doi: 10.1038/leu.2017.222

6. Conlan MG, Bast M, Armitage JO, Weisenburger DD. Bone Marrow Involvement by Non-Hodgkin's Lymphoma: The Clinical Significance of Morphologic Discordance Between the Lymph Node and Bone Marrow. Nebraska Lymphoma Study Group. JCO (1990) 8:1163-72. doi: 10.1200/ JCO.1990.8.7.1163 
7. Meads MB, Hazlehurst LA, Dalton WS. The Bone Marrow Microenvironment as a Tumor Sanctuary and Contributor to Drug Resistance. Clin Cancer Res (2008) 14:2519-26. doi: 10.1158/1078-0432.CCR-07-2223

8. Zhong W, Zhu Z, Xu X, Zhang H, Xiong H, Li Q, et al. Human Bone Marrow-Derived Mesenchymal Stem Cells Promote the Growth and DrugResistance of Diffuse Large B-Cell Lymphoma by Secreting IL-6 and Elevating IL-17A Levels. J Exp Clin Cancer Res (2019) 38:73. doi: 10.1186/ s13046-019-1081-7

9. Campbell J, Seymour JF, Matthews J, Wolf M, Stone J, Juneja S. The Prognostic Impact of Bone Marrow Involvement in Patients With Diffuse Large Cell Lymphoma Varies According to the Degree of Infiltration and Presence of Discordant Marrow Involvement. Eur J Haematol (2006) 76:473-80. doi: 10.1111/j.1600-0609.2006.00644.x

10. Chung R, Lai R, Wei P, Lee J, Hanson J, Belch AR, et al. Concordant But Not Discordant Bone Marrow Involvement in Diffuse Large B-Cell Lymphoma Predicts a Poor Clinical Outcome Independent of the International Prognostic Index. Blood (2007) 110:1278-82. doi: 10.1182/blood-2007-01070300

11. Choi SM, Betz BL, Perry AM. Follicular Lymphoma Diagnostic Caveats and Updates. Arch Pathol Lab Med (2018) 142:1330-40. doi: 10.5858/arpa.20180217-RA

12. Russell AE, Sneider A, Witwer KW, Bergese P, Bhattacharyya SN, Cocks A, et al. Biological Membranes in EV Biogenesis, Stability, Uptake, and Cargo Transfer: An ISEV Position Paper Arising From the ISEV Membranes and EVs Workshop. J Extracell Vesicles (2019) 8:1684862. doi: 10.1080/ 20013078.2019.1684862

13. Kalluri R, LeBleu VS. The Biology, Function, and Biomedical Applications of Exosomes. Science (2020) 367(6478):eaau6977. doi: 10.1126/science.aau6977

14. van Niel G, D'Angelo G, Raposo G. Shedding Light on the Cell Biology of Extracellular Vesicles. Nat Rev Mol Cell Biol (2018) 19(4):213-28. doi: $10.1038 / \mathrm{nrm} .2017 .125$

15. Siegel RL, Miller KD, Jemal A. Cancer Statistics, 2019. CA: A Cancer J Clin (2019) 69:7-34. doi: 10.3322/caac.21551

16. Alizadeh AA, Eisen MB, Davis RE, Ma C, Lossos IS, Rosenwald A, et al. Distinct Types of Diffuse Large B-Cell Lymphoma Identified by Gene Expression Profiling. Nature (2000) 403:503-11. doi: 10.1038/35000501

17. Chapuy B, Stewart C, Dunford AJ, Kim J, Kamburov A, Redd RA, et al. Molecular Subtypes of Diffuse Large B Cell Lymphoma Are Associated With Distinct Pathogenic Mechanisms and Outcomes. Nat Med (2018) 24:679-90. doi: 10.1038/s41591-018-0016-8

18. Schmitz R, Wright GW, Huang DW, Johnson CA, Phelan JD, Wang JQ, et al. Genetics and Pathogenesis of Diffuse Large B-Cell Lymphoma. N Engl $J$ Med (2018) 378:1396-407. doi: 10.1056/NEJMoa1801445

19. Wright GW, Huang DW, Phelan JD, Coulibaly ZA, Roulland S, Young RM, et al. A Probabilistic Classification Tool for Genetic Subtypes of Diffuse Large B Cell Lymphoma With Therapeutic Implications. Cancer Cell (2020) 37:551-68.e14. doi: 10.1016/j.ccell.2020.03.015

20. Sangaletti S, Iannelli F, Zanardi F, Cancila V, Portararo P, Botti L, et al. IntraTumour Heterogeneity of Diffuse Large B-Cell Lymphoma Involves the Induction of Diversified Stroma-Tumour Interfaces. EBioMedicine (2020) 61:103055. doi: 10.1016/j.ebiom.2020.103055

21. Kotlov N, Bagaev A, Revuelta MV, Phillip JM, Cacciapuoti MT, Antysheva Z, et al. Clinical and Biological Subtypes of B-Cell Lymphoma Revealed by Microenvironmental Signatures. Cancer Discov (2021) 11:1468-89. doi: 10.1158/2159-8290.CD-20-0839

22. Milpied P, Gandhi AK, Cartron G, Pasqualucci L, Tarte K, Nadel B, et al. Follicular Lymphoma Dynamics. Adv Immunol (2021) 150:43-103. doi: 10.1016/bs.ai.2021.05.002

23. Amé-Thomas P, Tarte K. The Yin and the Yang of Follicular Lymphoma Cell Niches: Role of Microenvironment Heterogeneity and Plasticity. Semin Cancer Biol (2014) 24:23-32. doi: 10.1016/j.semcancer.2013.08.001

24. Verdière L, Mourcin F, Tarte K. Microenvironment Signaling Driving Lymphomagenesis. Curr Opin Hematol (2018) 25:335-45. doi: 10.1097/ MOH.0000000000000440

25. International CLL-IPI working group. An International Prognostic Index for Patients With Chronic Lymphocytic Leukaemia (CLL-IPI): A Meta-Analysis of Individual Patient Data. Lancet Oncol (2016) 17:779-90. doi: 10.1016/ S1470-2045(16)30029-8
26. Hallek M. Chronic Lymphocytic Leukemia: 2020 Update on Diagnosis, Risk Stratification and Treatment. Am J Hematol (2019) 94:1266-87. doi: 10.1002/ajh.25595

27. Caligaris-Cappio F, Bertilaccio MTS, Scielzo C. How the Microenvironment Wires the Natural History of Chronic Lymphocytic Leukemia. Semin Cancer Biol (2014) 24:43-8. doi: 10.1016/j.semcancer.2013.06.010

28. Bognár Á, Csernus B, Bödör C, Reiniger L, Szepesi Á, Tóth E, et al. Clonal Selection in the Bone Marrow Involvement of Follicular Lymphoma. Leukemia (2005) 19:1656-62. doi: 10.1038/sj.leu.2403844

29. Dumontet E, Pangault C, Roulois D, Desoteux M, Léonard S, Marchand T, et al. Extracellular Vesicles Shed by Follicular Lymphoma B Cells Promote the Polarization of Bone Marrow Stromal Cell Niche. Blood (2021) 138 (1):57-70. doi: 10.1182/blood.2020008791

30. Wartenberg M, Vasil P, zum Bueschenfelde CM, Ott G, Rosenwald A, Fend F, et al. Somatic Hypermutation Analysis in Follicular Lymphoma Provides Evidence Suggesting Bidirectional Cell Migration Between Lymph Node and Bone Marrow During Disease Progression and Relapse. Haematologica (2013) 98:1433-41. doi: 10.3324/haematol.2012.074252

31. Araf S, Wang J, Korfi K, Pangault C, Kotsiou E, Rio-Machin A, et al. Genomic Profiling Reveals Spatial Intra-Tumor Heterogeneity in Follicular Lymphoma. Leukemia (2018) 32:1261-5. doi: 10.1038/s41375-018-0043-y

32. Baryawno N, Przybylski D, Kowalczyk MS, Kfoury Y, Severe N, Gustafsson K, et al. A Cellular Taxonomy of the Bone Marrow Stroma in Homeostasis and Leukemia. Cell (2019) 177:1915-32.e16. doi: 10.1016/ j.cell.2019.04.040

33. Tikhonova AN, Dolgalev I, Hu H, Sivaraj KK, Hoxha E, Cuesta-Domínguez Á, et al. The Bone Marrow Microenvironment at Single-Cell Resolution. Nature (2019) 569:222-8. doi: 10.1038/s41586-019-1104-8

34. Balzano M, De Grandis M, Vu Manh T-P, Chasson L, Bardin F, Farina A, et al. Nidogen-1 Contributes to the Interaction Network Involved in Pro-B Cell Retention in the Peri-Sinusoidal Hematopoietic Stem Cell Niche. Cell Rep (2019) 26:3257-71.e8. doi: 10.1016/j.celrep.2019.02.065

35. Chang K-C, Huang X, Medeiros LJ, Jones D. Germinal Centre-Like Versus Undifferentiated Stromal Immunophenotypes in Follicular Lymphoma. J Pathol (2003) 201:404-12. doi: 10.1002/path.1478

36. Kumar D, Xu ML. Microenvironment Cell Contribution to Lymphoma Immunity. Front Oncol (2018) 8:288. doi: 10.3389/fonc.2018.00288

37. Park Y, Park BB, Jeong JY, Kim WY, Jang S, Shin BK, et al. Assessment of Bone Marrow Involvement in Patients With Lymphoma: Report on a Consensus Meeting of the Korean Society of Hematology Lymphoma Working Party. Korean J Intern Med (2016) 31:1030-41. doi: 10.3904/ kjim.2015.006

38. Lamaison C, Tarte K. B Cell/Stromal Cell Crosstalk in Health, Disease, and Treatment: Follicular Lymphoma as a Paradigm. Immunol Rev (2021) 302:273-85. doi: 10.1111/imr.12983

39. Pangalis GA, Roussou PA, Kittas C, Mitsoulis-Mentzikoff C, MatsoukaAlexandridis P, Anagnostopoulos N, et al. Patterns of Bone Marrow Involvement in Chronic Lymphocytic Leukemia and Small Lymphocytic (Well Differentiated) Non-Hodgkin's Lymphoma. Its Clinical Significance in Relation to Their Differential Diagnosis and Prognosis. Cancer (1984) 54:702-8. doi: 10.1002/1097-0142(1984)54:4<702::aid-cncr2820540418>3.0.co;2-u

40. Pandey S, Mourcin F, Marchand T, Nayar S, Guirriec M, Pangault C, et al. IL-4/CXCL12 Loop Is a Key Regulator of Lymphoid Stroma Function in Follicular Lymphoma. Blood (2017) 129:2507-18. doi: 10.1182/blood-201608-737239

41. Lamaison C, Tarte K. Impact of B Cell/Lymphoid Stromal Cell Crosstalk in B-Cell Physiology and Malignancy. Immunol Lett (2019) 215:12-8. doi: 10.1016/j.imlet.2019.02.005

42. Mourcin F, Verdière L, Roulois D, Amin R, Lamaison C, Sibut V, et al. Follicular Lymphoma Triggers Phenotypic and Functional Remodeling of the Human Lymphoid Stromal Cell Landscape. Immunity (2021) 54:17881806.e7. doi: 10.1016/j.immuni.2021.05.019

43. Burger JA, Burger M, Kipps TJ. Chronic Lymphocytic Leukemia B Cells Express Functional CXCR4 Chemokine Receptors That Mediate Spontaneous Migration Beneath Bone Marrow Stromal Cells. Blood (1999) 94:3658-67. doi: 10.1182/blood.V94.11.3658

44. Burger JA, Tsukada N, Burger M, Zvaifler NJ, Dell'Aquila M, Kipps TJ. Blood-Derived Nurse-Like Cells Protect Chronic Lymphocytic Leukemia B 
Cells From Spontaneous Apoptosis Through Stromal Cell-Derived Factor-1. Blood (2000) 96:2655-63. doi: 10.1182/blood.V96.8.2655

45. Kurtova AV, Balakrishnan K, Chen R, Ding W, Schnabl S, Quiroga MP, et al. Diverse Marrow Stromal Cells Protect CLL Cells From Spontaneous and Drug-Induced Apoptosis: Development of a Reliable and Reproducible System to Assess Stromal Cell Adhesion-Mediated Drug Resistance. Blood (2009) 114:4441-50. doi: 10.1182/blood-2009-07-233718

46. Ponader S, Chen S-S, Buggy JJ, Balakrishnan K, Gandhi V, Wierda WG, et al. The Bruton Tyrosine Kinase Inhibitor PCI-32765 Thwarts Chronic Lymphocytic Leukemia Cell Survival and Tissue Homing In Vitro and In Vivo. Blood (2012) 119:1182-9. doi: 10.1182/blood-2011-10-386417

47. Möhle R, Failenschmid C, Bautz F, Kanz L. Overexpression of the Chemokine Receptor CXCR4 in B Cell Chronic Lymphocytic Leukemia Is Associated With Increased Functional Response to Stromal Cell-Derived Factor-1 (SDF-1). Leukemia (1999) 13:1954-9. doi: 10.1038/sj.leu.2401602

48. Till KJ, Lin K, Zuzel M, Cawley JC. The Chemokine Receptor CCR7 and Alpha4 Integrin Are Important for Migration of Chronic Lymphocytic Leukemia Cells Into Lymph Nodes. Blood (2002) 99:2977-84. doi: 10.1182/blood.v99.8.2977

49. Trentin L, Cabrelle A, Facco M, Carollo D, Miorin M, Tosoni A, et al. Homeostatic Chemokines Drive Migration of Malignant B Cells in Patients With Non-Hodgkin Lymphomas. Blood (2004) 104:502-8. doi: 10.1182/ blood-2003-09-3103

50. Capitani N, Patrussi L, Trentin L, Lucherini OM, Cannizzaro E, Migliaccio E, et al. S1P1 Expression Is Controlled by the Pro-Oxidant Activity of p66Shc and Is Impaired in B-CLL Patients With Unfavorable Prognosis. Blood (2012) 120:4391-9. doi: 10.1182/blood-2012-04-425959

51. Patrussi L, Capitani N, Martini V, Pizzi M, Trimarco V, Frezzato F, et al. Enhanced Chemokine Receptor Recycling and Impaired S1P1 Expression Promote Leukemic Cell Infiltration of Lymph Nodes in Chronic Lymphocytic Leukemia. Cancer Res (2015) 75:4153-63. doi: 10.1158/0008-5472.CAN-15-0986

52. Patrussi L, Capitani N, Cattaneo F, Manganaro N, Gamberucci A, Frezzato F, et al. p66Shc Deficiency Enhances CXCR4 and CCR7 Recycling in CLL B Cells by Facilitating Their Dephosphorylation-Dependent Release From $\beta$ Arrestin at Early Endosomes. Oncogene (2018) 37:1534-50. doi: 10.1038/ s41388-017-0066-2

53. Mcheik S, Van Eeckhout N, De Poorter C, Galés C, Parmentier M, Springael J-Y. Coexpression of CCR7 and CXCR4 During B Cell Development Controls CXCR4 Responsiveness and Bone Marrow Homing. Front Immunol (2019) 10:2970. doi: 10.3389/fimmu.2019.02970

54. Stamatopoulos B, Haibe-Kains B, Equeter C, Meuleman N, Sorée A, De Bruyn C, et al. Gene Expression Profiling Reveals Differences in Microenvironment Interaction Between Patients With Chronic Lymphocytic Leukemia Expressing High Versus Low ZAP70 mRNA. Haematologica (2009) 94:790-9. doi: 10.3324/haematol.2008.002626

55. Freitas C, Desnoyer A, Meuris F, Bachelerie F, Balabanian K, Machelon V. The Relevance of the Chemokine Receptor ACKR3/CXCR7 on CXCL12-Mediated Effects in Cancers With a Focus on Virus-Related Cancers. Cytokine Growth Factor Rev (2014) 25:307-16. doi: 10.1016/j.cytogfr.2014.04.006

56. Burger JA, Quiroga MP, Hartmann E, Bürkle A, Wierda WG, Keating MJ, et al. High-Level Expression of the T-Cell Chemokines CCL3 and CCL4 by Chronic Lymphocytic Leukemia B Cells in Nurselike Cell Cocultures and After BCR Stimulation. Blood (2009) 113:3050-8. doi: 10.1182/blood-2008-07-170415

57. Kurtova AV, Tamayo AT, Ford RJ, Burger JA. Mantle Cell Lymphoma Cells Express High Levels of CXCR4, CXCR5, and VLA-4 (CD49d): Importance for Interactions With the Stromal Microenvironment and Specific Targeting. Blood (2009) 113:4604-13. doi: 10.1182/blood-2008-10-185827

58. Sivina M, Xiao L, Kim E, Vaca A, Chen S-S, Keating MJ, et al. CXCL13 Plasma Levels Function as a Biomarker for Disease Activity in Patients With Chronic Lymphocytic Leukemia. Leukemia (2021) 35:1610-20. doi: 10.1038/ s41375-020-01063-7

59. Chen CC, Manning AM. Transcriptional Regulation of Endothelial Cell Adhesion Molecules: A Dominant Role for NF-Kappa B. Agents Actions Suppl (1995) 47:135-41. doi: 10.1007/978-3-0348-7343-7_12

60. Brachtl G, Sahakyan K, Denk U, Girbl T, Alinger B, Hofbauer SW, et al. Differential Bone Marrow Homing Capacity of VLA-4 and CD38 High Expressing Chronic Lymphocytic Leukemia Cells. PloS One (2011) 6:e23758. doi: 10.1371 /journal.pone. 0023758
61. Lin Z, Chen B, Wu T, Xu X. Highly Tumorigenic Diffuse Large B Cell Lymphoma Cells Are Produced by Coculture With Stromal Cells. AHA (2018) 139:201-16. doi: 10.1159/000488385

62. Lwin T, Crespo LA, Wu A, Dessureault S, Shu HB, Moscinski LC, et al. Lymphoma Cell Adhesion-Induced Expression of B Cell-Activating Factor of the TNF Family in Bone Marrow Stromal Cells Protects Non-Hodgkin's B Lymphoma Cells From Apoptosis. Leukemia (2009) 23:170-7. doi: 10.1038/ leu.2008.266

63. Grégoire M, Guilloton F, Pangault C, Mourcin F, Sok P, Latour M, et al. Neutrophils Trigger a NF-kb Dependent Polarization of Tumor-Supportive Stromal Cells in Germinal Center B-Cell Lymphomas. Oncotarget (2015) 6:16471-87. doi: 10.18632/oncotarget.4106

64. Blonska M, Zhu Y, Chuang HH, You MJ, Kunkalla K, Vega F, et al. JunRegulated Genes Promote Interaction of Diffuse Large B-Cell Lymphoma With the Microenvironment. Blood (2015) 125:981-91. doi: 10.1182/blood2014-04-568188

65. Monti S, Savage KJ, Kutok JL, Feuerhake F, Kurtin P, Mihm M, et al. Molecular Profiling of Diffuse Large B-Cell Lymphoma Identifies Robust Subtypes Including One Characterized by Host Inflammatory Response. Blood (2005) 105:1851-61. doi: 10.1182/blood-2004-07-2947

66. Caro P, Kishan AU, Norberg E, Stanley IA, Chapuy B, Ficarro SB, et al. Metabolic Signatures Uncover Distinct Targets in Molecular Subsets of Diffuse Large B Cell Lymphoma. Cancer Cell (2012) 22:547-60. doi: 10.1016/ j.ccr.2012.08.014

67. Gooptu M, Whitaker-Menezes D, Sprandio J, Domingo-Vidal M, Lin Z, Uppal G, et al. Mitochondrial and Glycolytic Metabolic Compartmentalization in Diffuse Large B-Cell Lymphoma. Semin Oncol (2017) 44:204-17. doi: 10.1053/ j.seminoncol.2017.10.002

68. Ricci J-E, Chiche J. Metabolic Reprogramming of Non-Hodgkin's B-Cell Lymphomas and Potential Therapeutic Strategies. Front Oncol (2018) 8:556. doi: $10.3389 /$ fonc. 2018.00556

69. Mintz MA, Cyster JG. T Follicular Helper Cells in Germinal Center B Cell Selection and Lymphomagenesis. Immunol Rev (2020) 296:48-61. doi: $10.1111 /$ imr. 12860

70. Vega F, Medeiros LJ, Lang W-H, Mansoor A, Bueso-Ramos C, Jones D. The Stromal Composition of Malignant Lymphoid Aggregates in Bone Marrow: Variations in Architecture and Phenotype in Different B-Cell Tumours. $\mathrm{Br} J$ Haematol (2002) 117:569-76. doi: 10.1046/j.1365-2141.2002.03497.x

71. Guilloton F, Caron G, Ménard C, Pangault C, Amé-Thomas P, Dulong J, et al. Mesenchymal Stromal Cells Orchestrate Follicular Lymphoma Cell Niche Through the CCL2-Dependent Recruitment and Polarization of Monocytes. Blood (2012) 119:2556-67. doi: 10.1182/blood-2011-08370908

72. Mraz M, Zent CS, Church AK, Jelinek DF, Wu X, Pospisilova S, et al. Bone Marrow Stromal Cells Protect Lymphoma B-Cells From Rituximab-Induced Apoptosis and Targeting Integrin $\alpha-4-\beta-1$ (VLA-4) With Natalizumab can Overcome This Resistance. Br J Haematol (2011) 155:53-64. doi: 10.1111/ j.1365-2141.2011.08794.x

73. Mourcin F, Pangault C, Amin-Ali R, Amé-Thomas P, Tarte K. Stromal Cell Contribution to Human Follicular Lymphoma Pathogenesis. Front Immunol (2012) 3:280. doi: 10.3389/fimmu.2012.00280

74. Plander M, Ugocsai P, Seegers S, Orsó E, Reichle A, Schmitz G, et al. Chronic Lymphocytic Leukemia Cells Induce Anti-Apoptotic Effects of Bone Marrow Stroma. Ann Hematol (2011) 90:1381-90. doi: 10.1007/s00277-011-1218-Z

75. Kim HS, Zhang X, Choi YS. Activation and Proliferation of Follicular Dendritic Cell-Like Cells by Activated T Lymphocytes. J Immunol (1994) 153:2951-61.

76. Lagneaux L, Delforge A, De Bruyn C, Bernier M, Bron D. Adhesion to Bone Marrow Stroma Inhibits Apoptosis of Chronic Lymphocytic Leukemia Cells. Leuk Lymphoma (1999) 35:445-53. doi: 10.1080/10428199909169609

77. Burger JA, Zvaifler NJ, Tsukada N, Firestein GS, Kipps TJ. Fibroblast-Like Synoviocytes Support B-Cell Pseudoemperipolesis via a Stromal CellDerived Factor-1- and CD106 (VCAM-1)-Dependent Mechanism. J Clin Invest (2001) 107:305-15. doi: 10.1172/JCI11092

78. Lee S, Van NT, Vachhani NB, Uthman M, Keating MJ, Juneja HS. Adhesion of B-Cell Chronic Lymphocytic Leukemia Cells to Marrow Stromal Cells Is Mediated by $\alpha 4 \beta 1$ But Not $\beta 2 \alpha$ Integrin: MSC Also Prevent Apoptosis of B-CLL Cells. Hematology (2001) 5:463-73. doi: 10.1080/10245332.2001.11746544 
79. Heinig K, Gätjen M, Grau M, Stache V, Anagnostopoulos I, Gerlach K, et al. Access to Follicular Dendritic Cells Is a Pivotal Step in Murine Chronic Lymphocytic Leukemia B-Cell Activation and Proliferation. Cancer Discovery (2014) 4:1448-65. doi: 10.1158/2159-8290.CD-14-0096

80. Endo T, Nishio M, Enzler T, Cottam HB, Fukuda T, James DF, et al. BAFF and APRIL Support Chronic Lymphocytic Leukemia B-Cell Survival Through Activation of the Canonical NF-kappaB Pathway. Blood (2007) 109:703-10. doi: 10.1182/blood-2006-06-027755

81. de Totero D, Meazza R, Capaia M, Fabbi M, Azzarone B, Balleari E, et al. The Opposite Effects of IL-15 and IL-21 on CLL B Cells Correlate With Differential Activation of the JAK/STAT and ERK1/2 Pathways. Blood (2008) 111:517-24. doi: 10.1182/blood-2007-04-087882

82. Pedersen IM, Kitada S, Leoni LM, Zapata JM, Karras JG, Tsukada N, et al. Protection of CLL B Cells by a Follicular Dendritic Cell Line is Dependent on Induction of Mcl-1. Blood (2002) 100:1795-801. doi: 10.1182/ blood.V100.5.1795.h81702001795_1795_1801

83. Granziero L, Circosta P, Scielzo C, Frisaldi E, Stella S, Geuna M, et al. CD100/Plexin-B1 Interactions Sustain Proliferation and Survival of Normal and Leukemic CD5+ B Lymphocytes. Blood (2003) 101:1962-9. doi: 10.1182/blood-2002-05-1339

84. Mangolini M, Götte F, Moore A, Ammon T, Oelsner M, Lutzny-Geier G, et al. Notch2 Controls Non-Autonomous Wnt-Signalling in Chronic Lymphocytic Leukaemia. Nat Commun (2018) 9:3839. doi: 10.1038/ s41467-018-06069-5

85. Nishio M, Endo T, Tsukada N, Ohata J, Kitada S, Reed JC, et al. Nurselike Cells Express BAFF and APRIL, Which can Promote Survival of Chronic Lymphocytic Leukemia Cells via a Paracrine Pathway Distinct From That of SDF-1alpha. Blood (2005) 106:1012-20. doi: 10.1182/blood-2004-03-0889

86. Richardson SJ, Matthews C, Catherwood MA, Alexander HD, Carey BS, Farrugia J, et al. ZAP-70 Expression Is Associated With Enhanced Ability to Respond to Migratory and Survival Signals in B-Cell Chronic Lymphocytic Leukemia (B-CLL). Blood (2006) 107:3584-92. doi: 10.1182/blood-2005-041718

87. Xu Z, Xiong D, Zhang J, Zhang J, Chen X, Chen Z, et al. Bone Marrow Stromal Cells Enhance the Survival of Chronic Lymphocytic Leukemia Cells by Regulating HES-1 Gene Expression and H3K27me3 Demethylation. Oncol Lett (2018) 15:1937-42. doi: 10.3892/ol.2017.7450

88. Zhang W, Trachootham D, Liu J, Chen G, Pelicano H, Garcia-Prieto C, et al. Stromal Control of Cystine Metabolism Promotes Cancer Cell Survival in Chronic Lymphocytic Leukaemia. Nat Cell Biol (2012) 14:276-86. doi: $10.1038 /$ ncb2432

89. Jitschin R, Braun M, Qorraj M, Saul D, Le Blanc K, Zenz T, et al. Stromal Cell-Mediated Glycolytic Switch in CLL Cells Involves Notch-C-Myc Signaling. Blood (2015) 125:3432-6. doi: 10.1182/blood-2014-10-607036

90. Yosifov DY, Idler I, Bhattacharya N, Reichenzeller M, Close V, Ezerina D, et al. Oxidative Stress as Candidate Therapeutic Target to Overcome Microenvironmental Protection of CLL. Leukemia (2020) 34:115-27. doi: 10.1038/s41375-019-0513-x

91. Amin R, Mourcin F, Uhel F, Pangault C, Ruminy P, Dupré L, et al. DCSIGN-expressing Macrophages Trigger Activation of Mannosylated IgM BCell Receptor in Follicular Lymphoma. Blood (2015) 126:1911-20. doi: 10.1182/blood-2015-04-640912

92. Epron G, Ame-Thomas P, Priol JL, Pangault C, Dulong J, Lamy T, et al. Monocytes and T Cells Cooperate to Favor Normal and Follicular Lymphoma B-Cell Growth: Role of IL-15 and CD40L Signaling. Leukemia (2012) 26:139-48. doi: 10.1038/leu.2011.179

93. Schwaller J, Schneider P, Mhawech-Fauceglia P, McKee T, Myit S, Matthes T, et al. Neutrophil-Derived APRIL Concentrated in Tumor Lesions by Proteoglycans Correlates With Human B-Cell Lymphoma Aggressiveness. Blood (2007) 109:331-8. doi: 10.1182/blood-2006-02-001800

94. Travert M, Ame-Thomas P, Pangault C, Morizot A, Micheau O, Semana G, et al. CD40 Ligand Protects From TRAIL-Induced Apoptosis in Follicular Lymphomas Through NF-kb Activation and Up-Regulation of C-FLIP and Bcl-xL. J Immunol (2008) 181:1001-11. doi: 10.4049/jimmunol.181.2.1001

95. Lee MJ, Park SY, Ko JH, Lee HJ, Ryu JS, Park JW, et al. Mesenchymal Stromal Cells Promote B-Cell Lymphoma in Lacrimal Glands by Inducing Immunosuppressive Microenvironment. Oncotarget (2017) 8:66281-92. doi: 10.18632/oncotarget.19971
96. Laurent C, Müller S, Do C, Al-Saati T, Allart S, Larocca LM, et al. Distribution, Function, and Prognostic Value of Cytotoxic T Lymphocytes in Follicular Lymphoma: A 3-D Tissue-Imaging Study. Blood (2011) 118:5371-9. doi: 10.1182/blood-2011-04-345777

97. Wahlin BE, Sander B, Christensson B, Østenstad B, Holte H, Brown PD, et al. Entourage: The Immune Microenvironment Following Follicular Lymphoma. Blood Cancer J (2012) 2:e52-2. doi: 10.1038/bcj.2011.53

98. Salmon H, Franciszkiewicz K, Damotte D, Dieu-Nosjean M-C, Validire P, Trautmann A, et al. Matrix Architecture Defines the Preferential Localization and Migration of T Cells Into the Stroma of Human Lung Tumors. J Clin Invest (2012) 122:899-910. doi: 10.1172/JCI45817

99. Béguelin W, Teater M, Meydan C, Hoehn KB, Phillip JM, Soshnev AA, et al. Mutant EZH2 Induces a Pre-Malignant Lymphoma Niche by Reprogramming the Immune Response. Cancer Cell (2020) 37:655-73.e11. doi: $10.1016 /$ j.ccell.2020.04.004

100. Boice M, Salloum D, Mourcin F, Sanghvi V, Amin R, Oricchio E, et al. Loss of the HVEM Tumor Suppressor in Lymphoma and Restoration by Modified CAR-T Cells. Cell (2016) 167:405-18.e13. doi: 10.1016/ j.cell.2016.08.032

101. Farinello D, Wozińska M, Lenti E, Genovese L, Bianchessi S, Migliori E, et al. A Retinoic Acid-Dependent Stroma-Leukemia Crosstalk Promotes Chronic Lymphocytic Leukemia Progression. Nat Commun (2018) 9:1787. doi: 10.1038/s41467-018-04150-7

102. Yeh Y-Y, Ozer HG, Lehman AM, Maddocks K, Yu L, Johnson AJ, et al. Characterization of CLL Exosomes Reveals a Distinct microRNA Signature and Enhanced Secretion by Activation of BCR Signaling. Blood (2015) 125:3297-305. doi: 10.1182/blood-2014-12-618470

103. Herishanu Y, Pérez-Galán P, Liu D, Biancotto A, Pittaluga S, Vire B, et al. The Lymph Node Microenvironment Promotes B-Cell Receptor Signaling, NF-kappaB Activation, and Tumor Proliferation in Chronic Lymphocytic Leukemia. Blood (2011) 117:563-74. doi: 10.1182/blood-2010-05-284984

104. Reiners KS, Shatnyeva O, Vasyutina E, Bösl T, Hansen HP, Hallek M, et al. Extracellular Vesicles Released From Chronic Lymphocytic Leukemia Cells Exhibit a Disease Relevant mRNA Signature and Transfer mRNA to Bystander Cells. Haematologica (2017) 102:e100-3. doi: 10.3324/haematol.2016.153197

105. Ghosh AK, Secreto CR, Knox TR, Ding W, Mukhopadhyay D, Kay NE. Circulating Microvesicles in B-Cell Chronic Lymphocytic Leukemia can Stimulate Marrow Stromal Cells: Implications for Disease Progression. Blood (2010) 115:1755-64. doi: 10.1182/blood-2009-09-242719

106. Kini AR, Kay NE, Peterson LC. Increased Bone Marrow Angiogenesis in B Cell Chronic Lymphocytic Leukemia. Leukemia (2000) 14:1414-8. doi: $10.1038 /$ sj.leu. 2401825

107. Gabrilove JL. Angiogenic Growth Factors: Autocrine and Paracrine Regulation of Survival in Hematologic Malignancies. Oncol (2001) 6:4-7. doi: 10.1634/theoncologist.6-suppl_5-4

108. Paggetti J, Haderk F, Seiffert M, Janji B, Distler U, Ammerlaan W, et al. Exosomes Released by Chronic Lymphocytic Leukemia Cells Induce the Transition of Stromal Cells Into Cancer-Associated Fibroblasts. Blood (2015) 126(9):1106-17. doi: 10.1182/blood-2014-12-618025

109. Kumarswamy R, Volkmann I, Jazbutyte V, Dangwal S, Park D-H, Thum T. Transforming Growth Factor- $\beta$-Induced Endothelial-to-Mesenchymal Transition Is Partly Mediated by microRNA-21. Arterioscler Thromb Vasc Biol (2012) 32:361-9. doi: 10.1161/ATVBAHA.111.234286

110. Zhu K, Pan Q, Zhang X, Kong L-Q, Fan J, Dai Z, et al. MiR-146a Enhances Angiogenic Activity of Endothelial Cells in Hepatocellular Carcinoma by Promoting PDGFRA Expression. Carcinogenesis (2013) 34:2071-9. doi: $10.1093 /$ carcin/bgt160

111. Hsieh J-Y, Huang T-S, Cheng S-M, Lin W-S, Tsai T-N, Lee OK, et al. miR146a-5p Circuitry Uncouples Cell Proliferation and Migration, But Not Differentiation, in Human Mesenchymal Stem Cells. Nucleic Acids Res (2013) 41:9753-63. doi: 10.1093/nar/gkt666

112. Li Q, Zhang D, Wang Y, Sun P, Hou X, Larner J, et al. MiR-21/Smad 7 Signaling Determines TGF- $\beta 1$-Induced CAF Formation. Sci Rep (2013) 3:2038. doi: 10.1038/srep02038

113. Yang Y, Li J, Geng Y. Exosomes Derived From Chronic Lymphocytic Leukaemia Cells Transfer miR-146a to Induce the Transition of Mesenchymal Stromal Cells Into Cancer-Associated Fibroblasts. J Biochem (2020) 168:491-8. doi: 10.1093/jb/mvaa064 
114. Farahani M, Rubbi C, Liu L, Slupsky JR, Kalakonda N. CLL Exosomes Modulate the Transcriptome and Behaviour of Recipient Stromal Cells and Are Selectively Enriched in miR-202-3p. PloS One (2015) 10:e0141429. doi: 10.1371/journal.pone.0141429

115. Crompot E, Damme MV, Pieters K, Vermeersch M, Perez-Morga D, Mineur P, et al. Extracellular Vesicles of Bone Marrow Stromal Cells Rescue Chronic Lymphocytic Leukemia B Cells From Apoptosis, Enhance Their Migration and Induce Gene Expression Modifications. Haematologica (2017) 102:1594-604. doi: 10.3324/haematol.2016.163337

116. Lobastova L, Lettau M, Babatz F, de Oliveira TD, Nguyen P-H, Pauletti BA, et al. CD30-Positive Extracellular Vesicles Enable the Targeting of CD30-Negative DLBCL Cells by the CD30 Antibody-Drug Conjugate Brentuximab Vedotin. Front Cell Dev Biol (2021) 9:698503. doi: 10.3389/ fcell.2021.698503

117. Zhang L, Zhou S, Zhou T, Li X, Tang J. Potential of the Tumor-Derived Extracellular Vesicles Carrying the Mir-125b-5p Target TNFAIP3 in Reducing the Sensitivity of Diffuse Large B Cell Lymphoma to Rituximab. Int J Oncol (2021) 58:31. doi: 10.3892/ijo.2021.5211

118. Zhang F, Li R, Yang Y, Shi C, Shen Y, Lu C, et al. Specific Decrease in B-CellDerived Extracellular Vesicles Enhances Post-Chemotherapeutic CD8+ T Cell Responses. Immunity (2019) 50:738-50.e7. doi: 10.1016/j.immuni.2019.01.010

119. Morse MA, Garst J, Osada T, Khan S, Hobeika A, Clay TM, et al. A Phase I Study of Dexosome Immunotherapy in Patients With Advanced Non-Small Cell Lung Cancer. J Transl Med (2005) 3:9. doi: 10.1186/1479-5876-3-9

120. Di Nicola M, Zappasodi R, Carlo-Stella C, Mortarini R, Pupa SM, Magni M, et al. Vaccination With Autologous Tumor-Loaded Dendritic Cells Induces Clinical and Immunologic Responses in Indolent B-Cell Lymphoma Patients
With Relapsed and Measurable Disease: A Pilot Study. Blood (2009) 113:1827. doi: 10.1182/blood-2008-06-165654

121. Pitt JM, Charrier M, Viaud S, André F, Besse B, Chaput N, et al. Dendritic Cell-Derived Exosomes as Immunotherapies in the Fight Against Cancer. J Immunol (2014) 193:1006-11. doi: 10.4049/jimmunol.1400703

122. Rivoltini L, Chiodoni C, Squarcina P, Tortoreto M, Villa A, Vergani B, et al. TNF-Related Apoptosis-Inducing Ligand (TRAIL)-Armed Exosomes Deliver Proapoptotic Signals to Tumor Site. Clin Cancer Res (2016) 22:3499-512. doi: 10.1158/1078-0432.CCR-15-2170

Conflict of Interest: The authors declare that the research was conducted in the absence of any commercial or financial relationships that could be construed as a potential conflict of interest.

Publisher's Note: All claims expressed in this article are solely those of the authors and do not necessarily represent those of their affiliated organizations, or those of the publisher, the editors and the reviewers. Any product that may be evaluated in this article, or claim that may be made by its manufacturer, is not guaranteed or endorsed by the publisher.

Copyright (c) 2021 Dumontet, Mancini and Tarte. This is an open-access article distributed under the terms of the Creative Commons Attribution License (CC BY). The use, distribution or reproduction in other forums is permitted, provided the original author(s) and the copyright owner(s) are credited and that the original publication in this journal is cited, in accordance with accepted academic practice. No use, distribution or reproduction is permitted which does not comply with these terms. 